\title{
Metode K-Means untuk Optimasi Klasifikasi Tema Tugas Akhir Mahasiswa Menggunakan Support Vector Machine (SVM)
}

\author{
Oman Somantri ${ }^{1}$, Slamet Wiyono ${ }^{2}$ Dairoh $^{3}$ \\ 1,2,3 Jurusan Teknik Informatika, Politeknik Harapan Bersama Tegal \\ Email: ${ }^{1}$ oman_mantri@yahoo.com, ${ }^{2}$ slamet2wiyono@gmail.com, ${ }^{3}$ dairoh@poltektegal.ac.id
}

\begin{abstract}
Abstrak
Masih sulitnya dalam menentukan klasifikasi tema tugas akhir mahasiswa sering dialami oleh setiap perguruan tinggi. Algoritma SVM digunakan untuk mengklasifikasi jenis tema tugas akhir mahasiswa. SVM merupakan metode yang banyak digunakan untuk klasifikasi. K-Means Clustering merupakan metode pengelompokan paling sederhana yang mengelompokkan data kedalam $k$ kelompok berdasar pada centroid masing-masing kelompok. Optimasi klasifikasi tema tugas akhir mahasiswa menggunakan SVM dan K-Means untuk meningkatkan tingkat akurasi. Hasil yang diperoleh memiliki tingkat akurasi yang lebih baik yaitu 86,21\%.
\end{abstract}

Kata Kunci: Text mining, Support Vector Machine, K-Means, Tugas Akhir

\section{PENDAHULUAN}

Mengambil mata kuliah tugas akhir atau skripsi merupakan kewajiban bagi setiap mahasiswa Diploma tingkat akhir, karena dengan tugas akhir itulah menentukan apakah mahasiswa tersebut lulus atau tidak dalam ujian sidang tugas akhir. Menentukan sebuah tema tugas akhir dan skripsi untuk mencari masalah penelitian menjadi salah satu kesulitan utama bagi mahasiswa, hal ini tentunya akan berpengaruh kepada tepat atau tidaknya mahasiswa tersebut lulus kuliah. Judul tugas akhir yang harus sesuai dengan tema untuk menjawab masalah penelitian yang telah ditentukan oleh setiap perguruan tinggi sesuai dengan jurusan yang diambil memberikan sebuah ketetapan bahwa judul tugas akhir yang diajukan oleh mahasiswa haruslah sesuai dengan jenis tema yang ditentukan.

Kesulitan yang dialami oleh banyak para pengambil kebijakan di perguruan tinggi dalam hal ini pada jurusan program studi adalah dalam menentukan klasifikasi tema dari judul tugas akhir yang diajukan oleh mahasiswa masih hanya berdasarkan intuisi, karena selama ini dalam penentukan klasifikasi jenis tema tugas akhir hanya berdasarkan pada perkiraan terhadap isi konten yang akan diteliti oleh mahasiswa sehingga kesesuaian antara judul dan tema berdasarkan pada teks judul terkadang diabaikan bahkan tidak sesuai.

Text mining merupakan pengembangan dari metode data mining yang dapat diterapkan untuk mengatasi permasalah terkait dengan pengklasifikasian tema judul tugas akhir mahasiswa [1]. Algoritma-algoritma dalam text mining dibuat untuk dapat mengenali data yang sifatnya semi terstruktur seperti sinopsis, abstrak maupun isi dari dokumen-dokumen. Kategori teks atau klasifikasi teks adalah suatu proses yang mengelompokan suatu teks kedalam suatu kategori tertentu [2]. Kategorisasi teks 
membuat pengelolaan informasi tersebut menjadi efektif dan efisien, sehingga dapat digunakan seperti untuk penyaringan terhadap email spam, melakukan penggalian opini (opinion mining), dan analisis sentimen. Algoritma kategorisasi teks saat ini telah banyak berkembang, antara lain Support Vector Machines (SVM), Nä̈ve Bayessian (NB), pohon keputusan, K-Nearest Neighbour (KNN), dan lainnya. Dari berbagai macam algoritma yang telah dikembangkan tersebut, KNN dan SVM telah diakui lebih handal dibandingkan dengan algoritma yang lainnya [3]. Pada penelitian yang dilakukan oleh Wulandini \& Nugroho (2009), membandingkan metode klasifikasi teks NBC dengan metode Support Vector machine (SVM), C4.5 dan $K$ Nearest Neighbour (K-NN), hasil penelitian menunjukkan akurasi masing-masing metode dari yang terbaik adalah SVM akurasi 92\%, NBC akurasi 90\% C4.5 akurasi $77.5 \%$ dan yang terendah K-NN akurasi $50 \%$ [4].

Algoritma Support Vector Machines (SVM) digunakan untuk klasifikasi penentuan jenis tema tugas akhir mahasiswa. SVM adalah metode yang banyak digunakan untuk klasifikasi data berupa text dengan tingkat akurasi yang lebih baik. Tetapi dalam hal ini untuk proses klasifikasi dokumen, seringkali ditemukan hasil yang kurang baik dikarenakan jumlah data dokumen yang besar dan bervariasi sehingga harus dikelompokkan terlebih dahulu [5]. Pada paper ini K-Means Clustering digunakan untuk memperbaiki proses klasifikasi data teks yang dilakukan yaitu dengan terlebih dahulu dilakukannya klasterisasi data agar tingkat akurasi model yang diusulkan menjadi lebih baik.

Penelitian terkait dengan klasifikasi tugas akhir dan skripsi telah dilakukan oleh beberapa peneliti, diantaranya Prilianti \& Wijaya (2014) meneliti mengenai pengembangan aplikasi berbasis text mining untuk automasi penentuan trend topik skripsi dengan metode K-Means Clustering [6]. Klasifikasi tugas akhir dan skripsi dengan algoritma $K$-Means clustering digunakan dalam proses penemun pola terbukti dapat membantu proses pengelompokan berbagai topik skripsi yang ada sehingga diperoleh informasi yang bermakna dalam menentukan tren penelitian Universitas dari tahun ke tahun.

Jiang, S., dkk., meneliti mengenai improve atau pengembangan model algoritma $K$ Nearest Neighbor untuk klasifikasi text. Dalam penelitian ini untuk mengoptimalisasi K-NN digunakan one pass clustering algorithm sehingga tingkat akurasi klasifikasi text menjadi lebih baik [7]. Penelitian selanjutnya dilakukan oleh Wangsa B.K, dkk., meneliti mengenai pembuatan sistem peringkat berita otomatis berbasis text mining menggunakan Generalized Vector Space Model dengan studi kasus berita diambil dari media masa online. Pada penelitian ini dihasilkan dengan menggunakan metode GVSM dapat diketahui kalimat mana yang lebiih berbobot terhadap suatu dokumen sehingga dapat dilakukan peringkasan dengan memperhatikan tingkat kemiripan kalimat dengan tingkat akurasi 94\%[8].

Dari ketiga penelitian sejenis tersebut diatas, berbeda dengan penelitian sebelumnya, yaitu untuk dapat meningkatkan tingkat akurasi pada SVM maka diterapkan algoritma $K$-Means sehingga tingkat akurasi untuk klasifikasi dalam penentuan tema tugas akhir mahasiswa sesuai dengan judul yang diajukan oleh mahasiswa terjadi peningkatan akurasi. 
Penggunaan text mining untuk mengklasifikasi jenis tema tugas akhir mahasiswa dengan menggunakan algoritma Support Vector Machines (SVM) dan dioptimalisasi dengan menggunakan $K$-Means Clustering untuk menghasilkan tingkat akurasi yang lebih baik.

\section{METODE}

\subsection{Text mining}

Text mining secara umum adalah teori tentang pengolahan koleksi dokumen dalam jumlah besar yang ada dari waktu ke waktu dengan menggunakan beberapa analisis, tujuan pengolahan teks tersebut adalah mengetahui dan mengekstrak informasi yang berguna dari sumber data dengan identifikasi dan eksplorasi pola menarik dalam kasus text mining, sumber data yang dipergunakan adalah kumpulan atau koleksi dokumen tidak terstuktur dan memerlukan adanya pengelompokan untuk diketahui informasi sejenis.

Text mining menurut Han \& Kamber, adalah satu langkah dari analisis teks yang dilakukan secara otomatis oleh komputer untuk menggali informasi yang berkualitas dari suatu rangkaian teks yang terangkum dalam sebuah dokumen. Prosedur utama dalam metode ini terkait dengan menemukan kata-kata yang dapat mewakili isi dari dokumen untuk selanjutnya dilakukan analisis keterhubungan antar dokumen dengan menggunakan metode statistik tertentu seperti analisis kelompok, klasifikasi dan asosiasi[9]. Tahapan dalam text mining secara umum diantaranya adalah tokenizing, filtering, stemming, tagging, dan analyzing [10].

\subsection{Support Vector Machine (SVM)}

Support Vector Machine (SVM) adalah metode klasifikasi yang bekerja dengan cara mencari hyperplane dengan margin terbesar hyperplane adalah garis batas pemisah data antar-kelas. Margin adalah jarak antara hyperplane dengan data terdekat pada masing-masing kelas. Adapun data terdekat dengan hyperplane pada masing-masing kelas inilah yang disebut support vector [11]. Pada dasarnya, SVM merupakan metode yang digunakan untuk klasifikasi dua kelas (binary classification). Pada perkembangannya, beberapa metode diusulkan agar SVM bisa digunakan untuk klasifikasi multi-class dengan cara mengombinasikan beberapa binary classifier [12]. Metode yang pernah diusulkan adalah metode One-against-one. Adapun untuk metode One-against-one, akan dikonstuksi sejumlah $k(k-1) / 2$ model klasifikasi SVM dengan masing-masing model dilatih menggunakan data dari dua kelas yang berbeda.

\subsection{K-Means Clustering}

Salah satu metode dalam pengelompokan dokumen adalah $\mathrm{K}$-Means Clustering. $\mathrm{K}$ Means Clustering merupakan metode pengelompokan paling sederhana yang mengelompokkan data kedalam $k$ kelompok berdasar pada centroid masing-masing kelompok. Hanya saja hasil dari K-Means sangat dipengaruhi parameter $k$ dan inisialisasi centroid. Pada umumnya K-Means menginisialisasi centroid secara acak. 
Namun metode yang diusulkan akan memodifikasi K-Means dalam inisialisasi centroid khususnya dalam memperbaiki performa dalam pengelompokan dokumen.

\subsection{Metode yang Digunakan}

Metode yang digunakan adalah penerapan K-Means sebagai model untuk meningkatkan tingkat akurasi untuk klasifikasi jenis tema tugas akhir mahasiswa dengan menggunakan Support Vector Machine (SVM), digambarkan seperti pada Gambar 1.

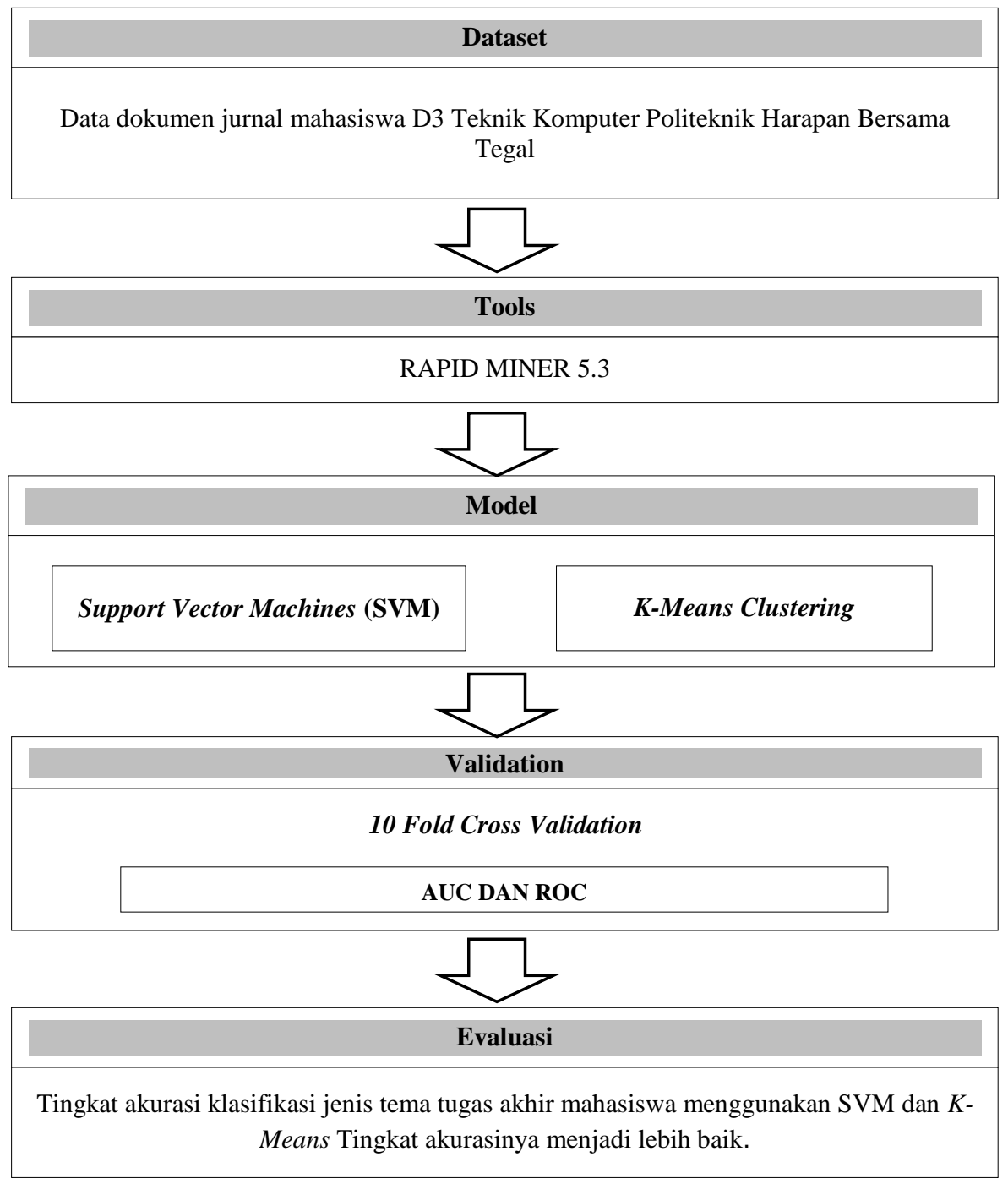

Gambar 1. Tahapan penelitian 


\subsection{Dataset dan Alat Penelitian}

Dataset diperoleh dari data jurnal mahasiswa D3 Tenik Komputer Politeknik Harapan Bersama Tegal tahun akademik 2014/2015, sebanyak 131 jurnal mahasiswa dengan berbagai macam jenis tema terdiri dari multimedia, pemrograman desktop, dan pemrograman web. Alat atau tools yang digunakan menggunakan Software Rapid Miner 5.0, sebagai pendukung pengolahan data menggunakan Ms. Excel 2007.

\subsection{Preprocessing Data}

Tahap awal sebelum melakukan proses pengelompokan dokumen adalah dengan mempersiapkan teks yang ada didalam dokumen. Pada tahap pra-proses ini dilakukan beberapa subproses agar dokumen dapat dipakai untuk melakukan proses pengelompokan. Subproses diantaranya yaitu dilakukan sebagai berikut:

a. Tokenizer, yakni proses yang bertujuan untuk memisah teks menjadi beberapa token berdasarkan pembatas berupa spasi atau tanda baca.

b. Proses selanjutnya adalah menghilangkan teks yang bersesuaian dengan teks yang terdapat pada daftar stopword, karena teks tersebut dianggap tidak dapat mewakili konten dokumen.

c. Kemudian pada teks yang masih tersisa dilakukan proses stemming, yaitu proses pengubahan teks menjadi bentuk dasarnya.

d. Selanjutnya, setiap kata tersebut disebut sebagai term. Nantinya setiap term akan didaftar dan diberi bobot.

e. Pembobotan masing-masing term dilakukan dengan metode TF-IDF (Term Frequency - Inverse Document Frequency). TF-IDF merupakan metode pembobotan term dengan menggunakan termfrequency (jumlah term yang terdapat pada tiap dokumen) serta inverse document frequency (invers jumlah dokumen yang memuat suatu term).

\subsection{Proses Pengelompokan Atau Kategorisasi Dokumen}

Proses pengelompokan dilakukan terhadap hasil pra-proses yang merupakan representasi data dalam bentuk model ruang vektor. Metode pertama ialah pengelompokan dokumen yang ada dengan K-Means Clustering. Kemudian setelah itu setiap kelompok dokumen tersebut akan diklasifikasi dengan Multi-Class SVM.

\subsection{Penentuan Data Training dan Testing}

Data training dan testing diambil dari judul tugas akhir mahasiswa program studi D3 Teknik Komputer Politeknik Harapan Bersama tegal yang diambil pada tahun 2013 dan 2014, dimana setelah dijumlahkan akan di split menjadi $70 \%$ data training dan $30 \%$ data testing.

\subsection{Eksperimen dan Pengujian}

Dari $k$ model klasifikasi yang telah ada, maka dapat dilakukan klasifikasi dokumen baru. Pengujian dilakukan dengan mengelompokkan dokumen baru kedalam 
kelompok yang ada menggunakan tetangga terdekat dari centroid pada masingmasing kelompok. Setelah didapatkan kelompok yang sesuai maka dilakukan proses klasifikasi dokumen baru dengan model Multi-class SVM pada kelompok yang bersangkutan.

\subsection{Evaluasi dan Validasi Penelitian}

Sebagai evaluasi dari model yang diusulkan, yaitu dengan menggunakan metode $K$ folds Cross validations untuk mencari nilai akurasi yang kemudian hasil dari akurasi tersebut dievaluasi dengan cara membandingkan tingkat akurasi yang dihasilkan oleh model SVM dengan menggunakan K-Means dan dengan model SVM tanpa K-Means

\section{HASIL DAN PEMBAHASAN}

\subsection{Pra-processing Data}

Sebelum dataset text diolah dengan menggunakan model yang akan digunakan, maka terlebih dahulu dataset yang berupa file bertipe .doc di convert menjadi file tipe txt. Hal ini dilakukan agar file text yang akan digunakan kedalam model dengan menggunakan tools rapid miner dapat terbaca dengan baik, gambaran proses perubahan file tersebut seperti tampak pada Gambar 2 dibawah ini.

File Data Text .doc

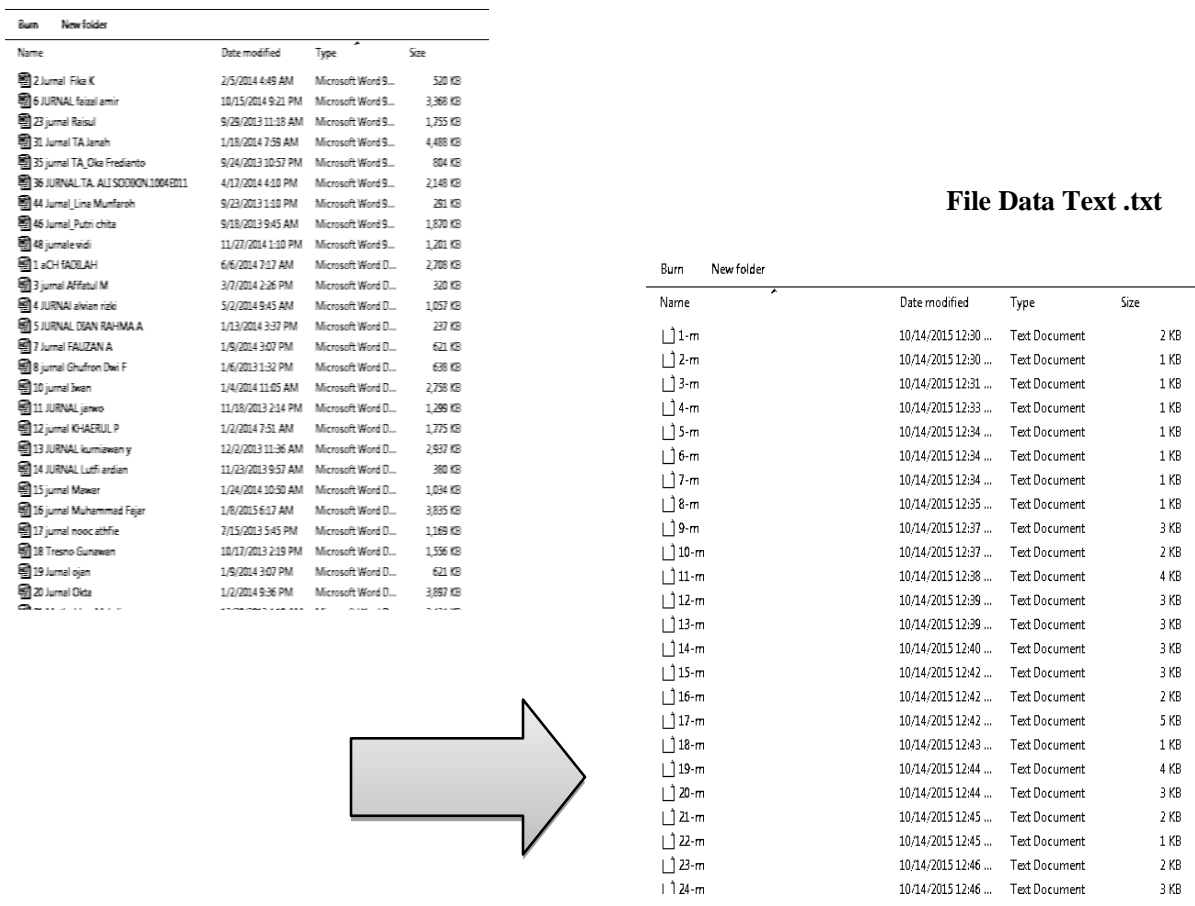

Gambar 2. Proses Perubahan file bertipe .doc kedalam tipe .txt 


\subsection{Tahapan Pengolahan Dokumen}

Pada tahapan selanjutnya adalah mengolah data text yang akan digunakan kedalam beberapa tahapan, agar nantinya diperoleh inputan dataset yang sesuai dengan model yang akan digunakan, diperlihatkan pada Gambar 3 dibawah ini:

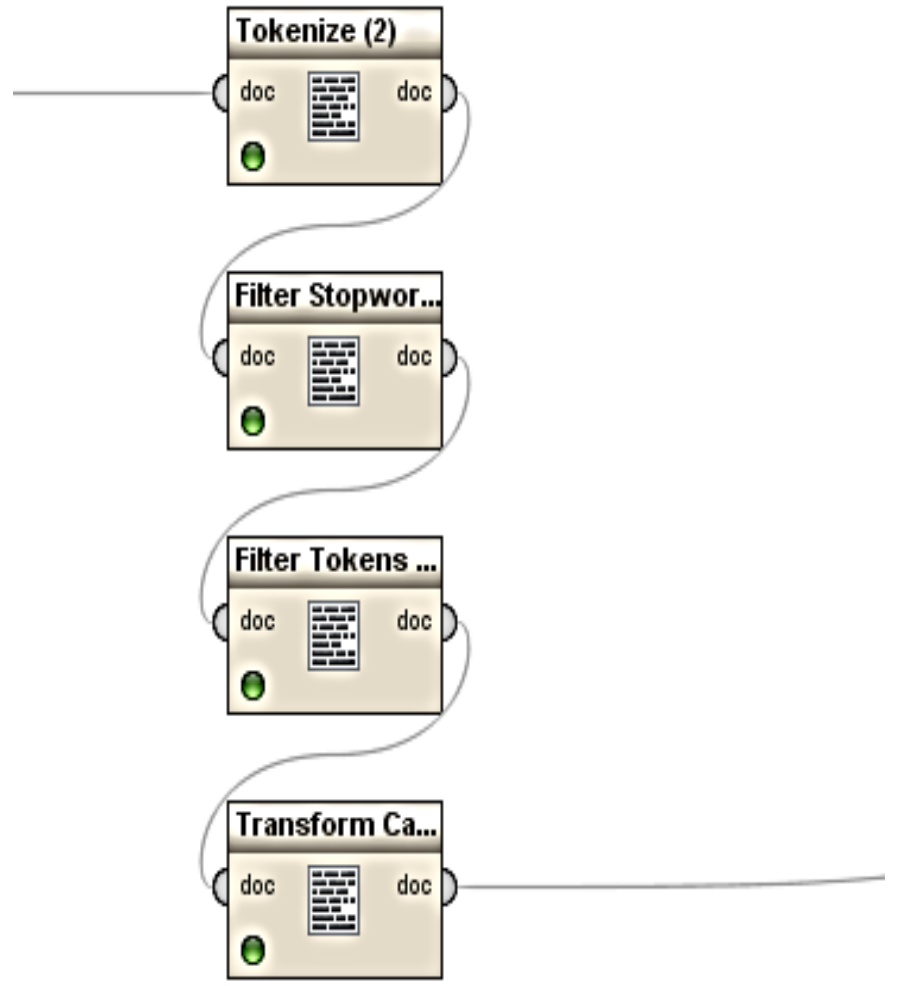

Gambar 3. Tahapan pengolahan dokumen

Seperti yang telah diperlihatkan pada Gambar 3, adapun tahapannya adalah sebagai berikut:

a. Tokenizer, yakni proses yang bertujuan untuk memisah teks menjadi beberapa token berdasarkan pembatas berupa spasi atau tanda baca.

b. Filter Stopword, yakni menghilangkan teks yang bersesuaian dengan teks yang terdapat pada daftar stopword, karena teks tersebut dianggap tidak dapat mewakili konten dokumen.

c. Filter Token: adalah memfilter teks dengan Min char=5 dan Max char=25.

d. Transforms cases: mentranformasikan teks kedalam lower case. 


\subsection{Pembobotan TF-IDF (Term Frequency - Inverse Document Frequency)}

TF-IDF merupakan metode pembobotan term dengan menggunakan termfrequency yaitu jumlah term yang terdapat pada tiap dokumen serta inverse document frequency yaitu invers jumlah dokumen yang memuat suatu term.

Tabel 1. Pembobotan dokumen

\begin{tabular}{ccccccccccccc}
\hline administrasi & administratif & administra.. & administrasi & adobe & agama & agenda & agung & agustus & ahmad & alvana & ajaran \\
\hline 0 & 0 & 0 & 0 & 0 & 0 & 0 & 0 & 0 & 0 & 0 & 0 \\
0 & 0 & 0 & 0 & 0 & 0 & 0 & 0 & 0 & 0 & 0 & 0 \\
0 & 0 & 0 & 0 & 0 & 0 & 0 & 0 & 0 & 0 & 0 & 0 \\
0 & 0 & 0 & 0 & 0 & 0 & 0 & 0,309 & 0 & 0 & 0 & 0 \\
0 & 0 & 0 & 0 & 0 & 0 & 0 & 0 & 0 & 0 & 0 & 0 \\
0,056 & 0 & 0 & 0 & 0 & 0 & 0 & 0 & 0 & 0 & 0 & 0 \\
0 & 0 & 0 & 0 & 0 & 0 & 0 & 0 & 0 & 0 & 0 & 0 \\
0 & 0 & 0 & 0 & 0,211 & 0 & 0 & 0 & 0 & 0 & 0 & 0 \\
0 & 0 & 0 & 0 & 0 & 0 & 0 & 0 & 0 & 0 & 0 & 0 \\
0 & 0 & 0 & 0 & 0 & 0 & 0 & 0 & 0 & 0 & 0 & 0 \\
017 & 0 & 0 & 0 & 0 & 0 & 0 & 0 & 0 & 0 & 0 & 0 \\
0 & 0 & 0 & 0 & 0 & 0 & 0 & 0 & 0 & 0 & 0 & 0 \\
0 & 0 & 0 & 0 & 0,151 & 0 & 0 & 0 & 0 & 0 & 0 & 0 \\
0 & 0 & 0 & 0 & 0 & 0 & 0 & 0 & 0 & 0 & 0 & 0 \\
0 & 0 & 0 & 0 & 0 & 0 & 0 & 0 & 0 & 0 & 0 & 0 \\
0 & 0 & 0 & 0 & 0 & 0 & 0 & 0 & 0 & 0 & 0 & 0 \\
0 & 0 & 0 & 0 & 0 & 0,104 & 0 & 0 & 0 & 0 & 0 & 0 \\
0 & 0 & 0 & 0 & 0 & 0,047 & 0 & 0 & 0 & 0 & 0 & 0 \\
0 & 0 & 0 & 0 & 0 & 0 & 0 & 0 & 0 & 0 & 0 & 0 \\
0 & 0 & 0 & 0 & 0 & 0 & 0 & 0 & 0 & 0 & 0 \\
0 & 0 & 0 & 0 & 0 & 0 & 0 & 0 & 0 & 0 & 0 \\
\hline
\end{tabular}

\subsection{Pembahasan}

\subsubsection{Klasifikasi Data dengan Support Vector Machines (SVM)}

Pada tahapan pemilihan model yang sesui dengan yang diinginkan, parameter SVM yang digunakan adalah seperti pada Tabel 3 .

Tabel 3. Parameter SVM

\begin{tabular}{ll}
\hline PARAMETER & VALUE \\
\hline Kernel type & $\operatorname{dot}$ \\
Kernel cache & 200 \\
$\mathrm{C}$ & 0.0 \\
Convergence epsilon & 0.001 \\
Max iteration & 100000 \\
\hline
\end{tabular}

Setelah dilakukan ekperimen, maka didapatkan hasil dari model SVM yang digunakan adalah seperti pada Tabel 4 .

Tabel 4. Hasil Akurasi model SVM

\begin{tabular}{lcccc}
\hline ACCURACY: $\mathbf{8 5 , 3 8 \%}$ & \multicolumn{3}{c}{} \\
\hline & TRUE.MULTIMEDIA & TRUE.DESKTOP & TRUE.WEB & CLASS \\
& & & & 0 \\
PRECISION \\
\cline { 2 - 5 } PRED.MULTIMEDIA & 24 & 0 & 5 & $100 \%$ \\
PRED.DESKTOP & 2 & 41 & 47 & $85,42 \%$ \\
PRED.WEB & 5 & 7 & $90,66 \%$ \\
CLASS RECALL & $77,42 \%$ & $85,42 \%$ & $90,38 \%$ & \\
\hline
\end{tabular}


Dari Tabel 4 diperlihatkan bahwa hasil tingkat akurasi klasifikasi yang dihasilkan adalah sebesar $85,38 \%$.

\subsubsection{Clustering Data dengan K-Means}

Pada tahapan yang telah dilakukan sebelumnya yaitu menggunakan SVM sebagai model yang digunakan, kemudian langkah berikutnya adalah melakukan eksperimen dengan terlebih dahulu melakukan clustering data yang ada dengan menggunakan $K$ Means, sehingga didapatkan hasilnya seperti pada Tabel 5.

Tabel 5. Hasil Clustering

\begin{tabular}{lll}
\hline CLUSTER & JUMLAH & LABEL \\
\hline Cluster 0: & 27 & Multimedia \\
Cluster 1: & 56 & Desktop \\
Cluster 2: & 48 & Web \\
\hline
\end{tabular}

Apabila dibuatkan grafik maka hasilnya akan tampak pada Gambar 4 dibawah ini.

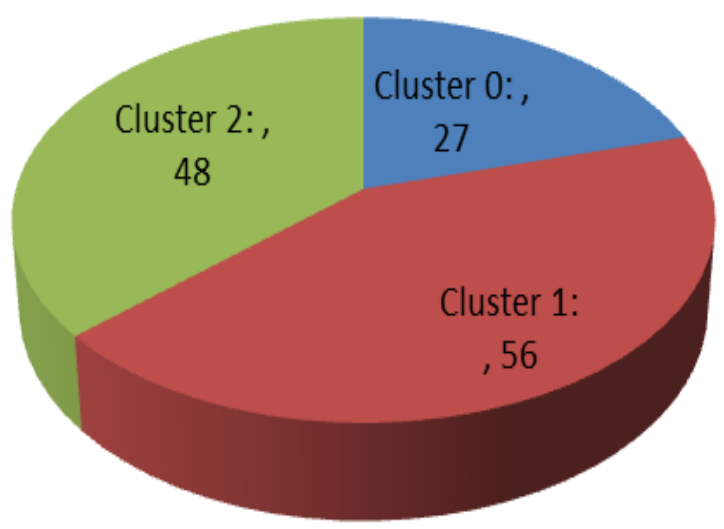

Gambar 4. Grafik Clustering dengan K-Means

\subsubsection{Improvement}

Berdasarkan ekperimen sebelumnya, maka untuk meningkatkan tingkat akurasi klasifikasi teks, diguanakan model hybrid yaitu menggunakan Support Vector Machines (SVM) dan K-Means Clustering. Setelah dilakukan eksperimen maka hasilnya didapatkan sebagai berikut: 
Tabel 6. Hasil akurasi SVM dan K-Means

\begin{tabular}{lcccc}
\hline ACCURACY: 86,21\% & \multicolumn{3}{c}{} \\
\hline & TRUE.MULTIMEDIA & TRUE.DESKTOP & TRUE.WEB & CLASS \\
& & & & 0 \\
PRECISION \\
\cline { 2 - 5 } PRED.MULTIMEDIA & 24 & 0 & 4 & $96,00 \%$ \\
PRED.DESKTOP & 1 & 41 & 47 & $89,13 \%$ \\
PRED.WEB & 6 & 6 & $92,00 \%$ \\
CLASS RECALL & $77,42 \%$ & $85,42 \%$ & $91 \%$ & \\
\hline
\end{tabular}

Dari Tabel diperlihatkan bahwa tingkat akurasi yang dihasilkan adalah sebesar $86,21 \%$.

\subsubsection{Evaluasi Model}

Berdasarkan hasil analisis yang telah dilakukan sebelumnya, maka untuk mengevaluasi hasil dari ekperimen didapatkan hasilnya sebagai berikut:

Tabel 7. Evaluasi model

\begin{tabular}{ll}
\hline MODEL & AKURASI \\
\hline SVM & $\mathbf{8 5 , 3 8 \%}$ \\
SVM + K-Means & $\mathbf{8 6 , 2 1 \%}$ \\
\hline
\end{tabular}

Dari hasil Tabel 7 diperlihatkan bahwa setelah dilakukan eksperimen terdapat perbedaan antara model dari SVM dibandingkan dengan model SVM + K-Means, dimana tingkat akurasi sebelumnya $85,38 \%$ menjadi $86,21 \%$.

\section{Akurasi}

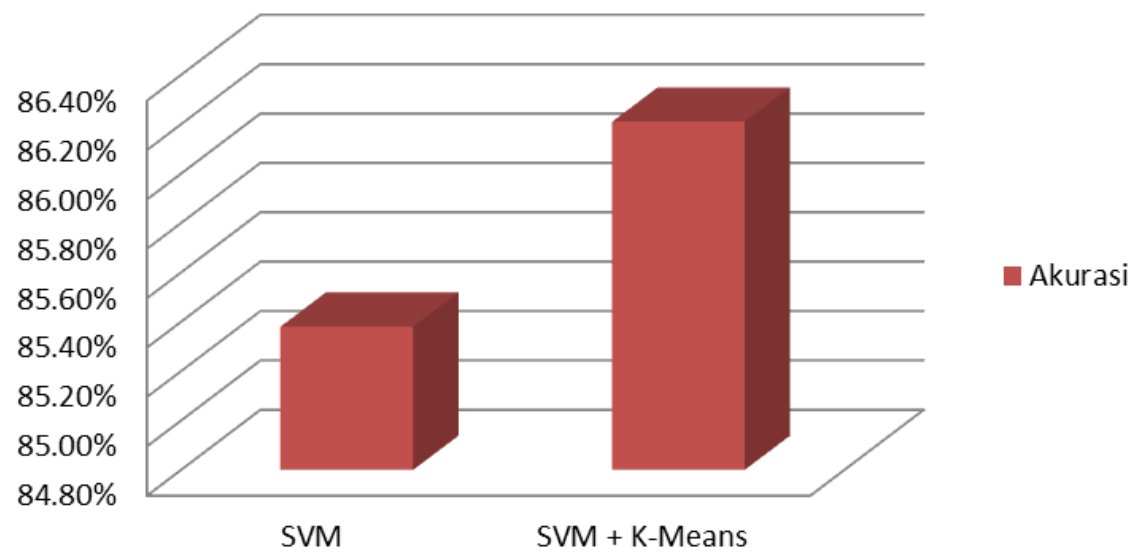

Gambar 5. Grafik perbandingan tingkat akurasi SVM dan SVM+K-Means 


\section{SIMPULAN}

Berbagai upaya dilakukan untuk dapat meningkatkan tingkat akurasi sebuah model khususnya pada text mining. Untuk meningkatkan tingkat akurasi pada prediksi klasifikasi data dokumen jenis tema tugas akhir mahasiswa, maka model algoritma KMeans digunakan sebelum dimasukan kedalam model Support Vector Machine (SVM). Dari analisis yang telah dilakukan dapat diambil kesimpulan bahwa model SVM dan K-Means dapat digunakan oleh para pengambil kebijakan dalam menglasifikasikan kategori tugas akhir sebagai pendukung keputusan dalam penentuan tema tersebut. K-Means menjadi model untuk optimalisasi untuk dapat meningkatkan tingkat akurasi model SVM dalam mengklasifikasikan kategori tema tugas akhir.

\section{REFERENSI}

[1] Gupta V. 2009. A Survey of Text Mining Techniques and Application. Journal of Emerging Technologies in Web Intelligence. Vol. 1: 60-75

[2] Sebastiani F. 2002. Machine Learning in Automated Text Categorization. ACM Computing Surveys. Vol. 34(1): 1-47

[3] Yang Y., \& Liu X. 1999. A Re-Examination of Text Categorization Methods. In Proceedings 22nd Annual International ACM SIGIR Conference on Research and Development in Information Retrieval (SIGIR-99). Berkeley: 42-49.

[4] Wulandini F \& Nugroho A.N. 2009. Text Classification Using Support Vector Machine for Web mining Based Spation Temporal Analysis of the Spread of Tropical Diseases. International Conference on Rural Information and Communication Technology.

[5] Trivedi S, Pardos A \& Sar N. 2008. Spectral Clustering in Educational Data Mining. Department of Computer Science, Worcester Polytechnic Institute.

[6] Prilianti KR \& Wijaya H. 2014. Aplikasi Text Mining untuk Automasi Penentuan Tren Topik Skripsi dengan Metode K-Means Clustering, Jurnal Cybermatika, Vol. 2(1).

[7] Jiang S., Pang G., Wu M., \& Kuang L. 2012. An Improved K-NearestNeighbor Algorithm for Text Categorization. In Expert Systems With Applications.

[8] Wangsa B.K., Utomo D., \& Nugroho S. 2014. Sistem Peringkas Berita Otomatis berbasis Text Mining menggunakan Generalized Vector Space Model: STudi Kasus Berita diambil dari media Massa Online. Techne Jurnal Ilmiah Elektroteknika. Vol. 1(2) Oktober: 231-241.

[9] Han, J., \& Kamber, M. 2006. Data Mining: Concepts and Techniques, University of Illinois at Urbana-Champaign.

[10] Berry, M. W. 2004. Survey of text mining. Computing Reviews. Vol 45(9): 548.

[11] Yunliang, J., Qing, S., Jing, F., \& Xiongtao, Z. 2010. The Classification for Egovernment Document Based on SVM. In Web Information Systems and Mining (WISM), 2010 International Conference on.Vol. 2: 257-260. 
[12] J.Z. Liang. 2004. SVM Multi-Classifier And Web Document Classification. Proceedings of the IEEE Third International Conference on Machine Learning and Cybernetics. 